\title{
PERAN SERTA PETERNAK SAPI PERAH DALAM PENGELOLAHAN BIOGAS MENUJU DAERAH ZERO WASTE
}

\section{The Role and Role of Dairy Cattle Farmers in Biogas Processing Towards the Zero Waste Region}

\author{
Dyah Triasih $^{1}$,Erik Febrianto ${ }^{1}$, Nurul Aqila Maulidya ${ }^{1}$, dan Laily Tahajjudy ${ }^{1}$ \\ ${ }^{1}$ Teknologi Pengolahan Hasil Ternak, Politeknik Negeri Banyuwangi \\ E-mail: triasihdyah@gmail.com
}

\begin{abstract}
ABSTRAK
Penelitian ini bertujuan untuk mengetahui peran serta peternak dalam pengelolahan biogas menuju daerah zero waste desa Glagahagung, Kecamatan Purwoharjo, Kabupaten Banyuwangi, Jawa Timur. Penelitian ini dilaksanakan pada bulan Juni sampai dengan Agustus 2020, dengan mengambil sampel sekitar 35 responden dari peternak sapi perah sekaligus melakukan pendampingan tentang bagaimana cara pembuatan biogas dan pupuk yang berasal dari slurry biogas. Hasil penelitian ini menunjukkan bahwa peran peternak dalam pengelolaan limbah kotoran sapi cukup baik, hal ini dapat dilihat dari inisiatif yang sudah terbentuk, serta antusiasme peternak dalam mengolah limbah kotoran sapi menjadi biogas dan pupuk dari slurry dan keberhasilan peran masyarakat dalam mengelola limbah kotoran sapi secara komprehensif.
\end{abstract}

Kata kunci: Biogas, Pendampingan, Limbah Kotoran Sapi, Slurry, Zero waste

\begin{abstract}
This study aims to determine the role of breeders in the processing of biogas towards the Zero waste area of Glagahagung Village, Purwoharjo District, Banyuwangi Regency, East Java. This research was conducted from June to August 2020, by taking a sample of about 35 respondents from dairy farmers while assisting with how to make biogas and fertilizers from biogas slurry. The results of this study indicate that the role of breeders in managing cow dung is quite good, this can be seen from the initiatives that have been formed, as well as the enthusiasm of farmers in processing cow dung waste into biogas and fertilizer from slurry and the success of the community's role in managing cow manure comprehensively.
\end{abstract}

Keywords: Biogas, Accompaniment, Cattle Manure Waste, Slurry, Zero Waste

\section{PENDAHULUAN}

Desa Glagahagung merupakan wilayah yang terletak di Kecamatan Purwoharjo, Kabupaten Banyuwangi, Jawa Timur. Desa Glagahagung memiliki luas wilayah 1.277,73 hektar yang merupakan campuran dari beberapa wilayah pemukiman, persawahan, dan hutan jati produksi. Desa Glagahagung berada di kawasan dataran rendah yang beriklim tropis. Namun masyarakatnya memilik pekerjaan memelihara sapi perah produktif dan mampu menghasilkan produksi ribuan liter susu segar per hari. Limbah yang dihasikan dari kelompok peternak digunakan sebagai pupuk organik oleh sebagian masyarakat dan juga kotoran sapi dimanfaatkan untuk dijadikan biogas yang dapat digunakan sebagai sumber bahan bakar alternatif pengganti kayu bakar, Gas LPG. Sisa dari biogas yang berupa slurry dimanfaatkan sebagai pupuk organik yang dapat diaplikasikan pada tanaman rumput gajah dan dimanfaatkan untuk pakan ternak. 
Limbah peternakan menjadi permasalahan utama dalam dunia peternakan karena mempunyai dampak yang buruk bagi masyarakat dan lingkungan, seperti bau tidak sedap yang ditimbulkan oleh gas berasal dari kotoran ternak terutama gas amoniak $\left(\mathrm{NH}_{3}\right)$ dan gas hidrogen $\left(\mathrm{H}_{2} \mathrm{~S}\right)$, keberadaannya dapat mencemari lingkungan, mengganggu pemandangan karena berserakan dan dapat memicu penyakit yang tidak diinginkan, oleh karena itu perlu adanya penanganan untuk masalah tersebut (Wahyuni, 2015). Di beberapa daerah di Indonesia, masyarakat telah memanfaatkan limbah kotoran sapi menjadi suatu keuntungan seperti biogas. Hasil dari biogas ialah berupa bahan bakar rumah tangga, bahan bakar kendaraan, dan menghasilkan listrik. Adapun hasil samping yang dapat dimanfaatkan dari biogas ialah ampas biogas yang dapat diolah menjadi pupuk cair biasa disebut dengan bio-slurry yang dapat diaplikasikan pada tanaman pertanian sehingga tidak ada limbah yang tersisa. Ciri utama dari pengintegrasian ternak dengan tanaman adalah keterkaitan yang saling menguntungkan antara tanaman dengan ternak. Keterkaitan tersebut terlihat dari pembagian lahan yang saling terpadu dan pemanfaatan limbah dari masing masing komponen. Sistem integrasi merupakan faktor pemicu dalam mendorong pertumbuhan pendapatan masyarakat tani dan pertumbuhan ekonomi wilayah yang berkelanjutan.

Peternakan di Indonesia sebagian besar merupakan usaha peternakan berskala kecil atau usaha ternak rakyat. Oleh karenanya permasalahan lingkungan dan kesehatan terkait dengan peternakan kurang diperhatikan. Kurangnya pengetahuan dan inovasi menjadi penyebab lambatnya perkembangan terkait pada bidang peternakan. Peternak di Indonesia masih menerapkan metode tradisional, peternak perlu mendapatkan informasi tentang teknologi dan inovasi. Tantangan terbesar untuk mencapai keberhasilan pembangunan peternakan adalah bagaimana mendorong dan menumbuh kembangkan agar peternak menjadi lebih berkualitas dan berdaya. Salah satu tujuan utama untuk merubah pola pikir peternak yang berkualitas, agar masyrakat dapat memanfaatkan semua peluang yang ada dalam peternakannya.

Kajian utama dalam mencari solusi permasalahan ini adalah mengenai pengelolaan kotoran sapi perah agar tidak menjadi penyebab pencemaran bagi masyarakat sekitar. Pemanfaatan kotoran sapi menjadi barang yang mempunyai nilai jual dengan pengelolaan yang komprehensif dari masih menjadi mentah sampai siap digunakan. Penanganan kotoran sapi yang bersifat komprehensif di Kecamatan Glagahagung belum sepenuhnya terwujud, untuk itu diharapkan dapat mendorong kearah komprehensif sudah mulai muncul. Sehingga kajian ini bertujuan untuk mengetahui bagaimana potensi peran serta masyarakat dalam pengelolaan kotoran sapi secara komprehensif menuju Zero Waste yang timbul dari peternakan sapi perah skala rakyat.

\section{METODE PELAKSANAAN}

Penelitian ini dilaksanakan antara bulan juni sampai dengan bulan agustus 2020 bertempat di Peternakan Lembu Makmur Glagahagung. Materi dan metode yang dirancang sebagai penelitian survei yang bersifat deskriptif. Unit analisis dari penelitian ini adalah kelompok peternak sapi perah yang ada di kecamatan Glagahagung. Dipilih kecamatan tersebut, karena merupakan salah satu wilayah konsentrasi kelompok dan peternak serta ternak sapi perah di kabupaten Banyuwangi. Sampel responden adalah para anggota kelompok dari seluruh kelompok tani ternak sapi perah yang ada di kecamatan Glagahagung, yang diambil secara proporsional. Jumlah kelompok peternak yang aktif sebanyak 7 kelompok dan jumlah responden yang akan diambil seluruhnya adalah 35 peternak. Variabel yang ditelaah meliputi peran kelompok ternak sebagai variabel bebas, dan keberdayaan peternak sebagai variabel terikat. 


\section{HASIL DAN PEMBAHASAN}

Desa Glagahagung merupakan desa yang memiliki potensi untuk membangun sektor pertanian dan peternakan, karena memiliki lahan yang cukup luas. Namun kebanyakan dari masyarakat yang beternak belum memiliki keterampilan akan teknologi. Dengan demikian dapat dilakukan pendampingan kepada peternak mengenai bagaimana mengolah hasil limbah dan dimanfaatkan kembali kepada tanaman tani. Teknologi yang dapat diterapkan yaitu dengan pembuatan biogas. Pengolahan kotoran sapi tidak hanya akan menghasil biogas yang dapat digunakan oleh masyarakat setempat, juga perlu untuk mengatasi polusi udara dan banyak penyakit yang timbul dari serakan kotoran sapi yang selama ini tidak terolah. Biogas merupakan gas yang dihasilkan dari bahan organik, limbah pertanian, atau kotoran hewan melalui proses fermentasi anaerobik yang dibantu dengan air.

\section{Aspek Pemahaman (Sosialisai Pengolahan Limbah)}

Selama ini peternak langsung membawa feses ke kebun tanpa melakukan pengomposan terlebih dahulu. Feses tersebut masih bersifat panas dan bisa mengganggu pertumbuhan tanaman. Dari kebiasaan ini sebenarnya bisa dikembangkan instalasi biogas. Dengan instalasi ini, peternak akan mendapatkan gas sebagai bahan bakar, pupuk organik padat, dan pupuk organik cair dari sisa fermentasi bahan organik dalam digester biogas. Selain itu, dapat mengurangi pencemaran akibat tumpukan feses. Faktor penyebab yang umum adalah ketersediaan hijauan, replacement stock, infrasruktur, cekaman panas dari iklim tropis di Indonesia. Cekaman panas telah dapat diatasi dengan manipulasi iklim mikro dengan perbaikan struktur kandang, penambahan kipas angin, bahan atap yang tahan radiasi panas dan usaha lainya agar sapi perah berada di kondisi yang nyaman sehingga mampu meningkatkan konsumsi pakannya. Ketersediaan hijauan juga merupakan masalah yang sering dihadapi oleh peternak. Oleh karenanya, hasil dari pembuatan biogas yang menghasilkan gas, menjadi sumber energi alternatif terbarukan pengganti bahan bakar seperti kayu bakar, LPG rumah tangga, juga hasil samping berupa ampas yang dihasilkan selama proses fermentasi biogas yaitu berupa bio-slurry yang dapat dimanfaatkan pada tanaman pertanian maupun perkebunan kemudian hasil dari tanaman pertanian dapat digunakan sebagai pakan ternak kembali.

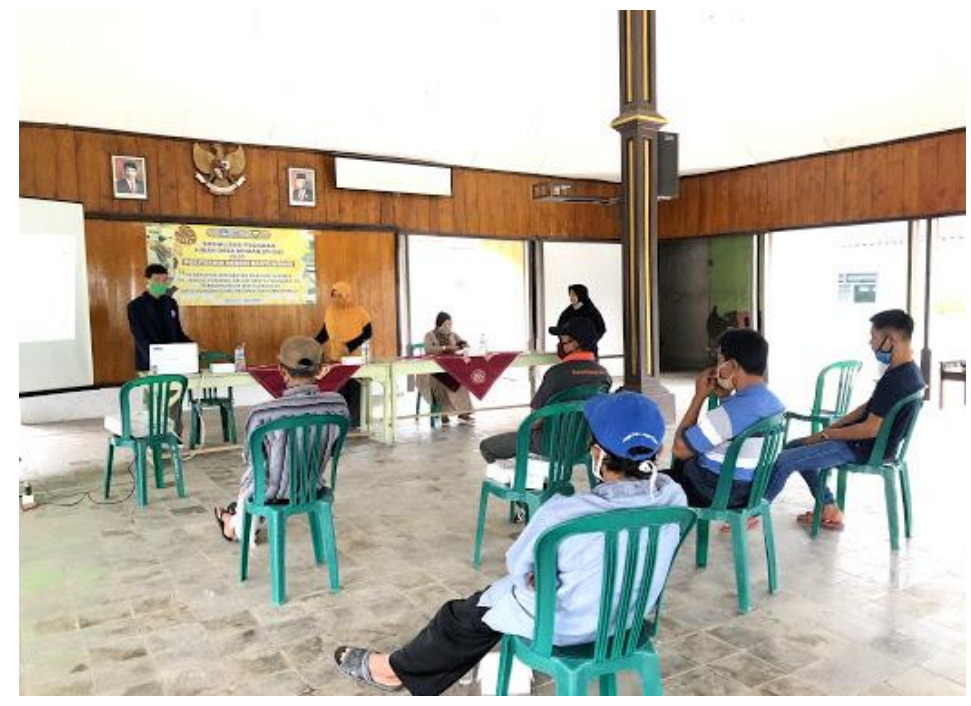

Gambar 1. Kegiatan Pendampingan

Pada proses pendampingan dilaksanakan untuk menawarkan konsep tentang bagaimana cara pengelolaan limbah peternakan menjadi sumber alternatif bahan bakar yang bermanfaat. Proses 
pendampingan dengan pemanfaatan kotoran ternak merupakan sebuah kegiatan yang dimana hasil limbah menjadi timbal balik bagi peternak. Proses ini mulai berjalan setelah peralatan dan perlengkapan sudah tersedia untuk masyarakat. Tahap ini berkaitan dengan teknis penggunaan peralatan yang ada dan pengenalan mengenai teknis pengelolaan.

Berdasarkan data yang kami kumpulkan melalui kuesioner, pendapat masyarakat tentang pentingnya kegiatan pendampingan pengelolaan limbah tercantum dalam Tabel 1 berikut :

Tabel 1. Pentingnya Kegiatan Pendampingan Pengelolaan Limbah Sebagai Biogas

\begin{tabular}{rlc}
\hline Kegiatan Pendampingan Pengelolaan Limbah Sebagai Biogas & $\%$ \\
\hline 1. & $\begin{array}{l}\text { Sangat penting karena membantu dalam memberikan gambaran } \\
\text { mengenai pengolahan limbah sebagai biogas }\end{array}$ & $86 \%$ \\
2. $\begin{array}{l}\text { Kurang begitu penting karena limbah peternakan dapat dibuang } \\
\text { begitu saja atau dialirkan ke sungai }\end{array}$ & $11 \%$ \\
3. Tidak penting sama sekali & $3 \%$ \\
\hline \multicolumn{1}{c}{ TOTAL } & $100 \%$ \\
\hline
\end{tabular}

Berdasarkan data hasil tersebut dapat diketahui, bahwa peran kegiatan pendampingan pengolahan kotoran ternak sapi perah sebagai biogas sangat penting, (86\%) dapat diterima oleh masyarakat peternak karena berguna untuk membantu penanganan mengenai manfaat yang diperoleh dari pembuatan biogas. Dan masyarakat yang menanggapi pendampingan yang kurang penting hanya $11 \%$ sedangkan yang menganggap kegiatan pendampingan tidak penting sebesar $3 \%$.

\section{Aspek Proses Pengolahan}

Proses pembuatan biogas meliputi beberapa tahapan yaitu 1) Bahan input biogas (berupa kotoran ternak segar) dicampur dengan air, 2) Campuran tersebut diaduk, kemudian, dialirkan ke dalam reaktor biogas sampai batas optimal lubang pengeluaran, 3) Didiamkan selama 2-3 minggu, dengan posisi kran gas pengeluaran ke kompor dalam keadaan tertutup, 4) Hasil proses fermentasi terlihat pada akhir minggu ke 2, karena sifatnya ringan biogas akan terkumpul di bagian atas tabung reaktor, 5) Gas pertama yang terbentuk dikeluarkan dengan ditandai menggembungnya penampung plastik biogas sampai keluar bau khas biogas, 6) Pada saat biogas matang komposisi yang dihasilkan yaitu berupa $\mathrm{CH}_{4} 54 \%$ dan $\mathrm{CO}_{2} 27 \%$, sehingga biogas akan menyala pada saat didekatkan dengan sumber panas (korek api). Produksi biogas akan berlangsung secara terus menerus, tergantung pengisian dan pemeliharaan instalasi.

Tabel 2. Pengolahan Limbah Ternak

\begin{tabular}{|c|c|}
\hline Bagaimana Cara Pengolahan Limbah Ternak & $\begin{array}{c}\text { Persentase } \\
\quad(\%)\end{array}$ \\
\hline $\begin{array}{l}\text { 1. Melakukan pengumpulan kotoran ternak dan perakitan diegester } \\
\text { biogas }\end{array}$ & $45 \%$ \\
\hline $\begin{array}{l}\text { 2. Proses pengenceran dan pencampuran kotoran dengan air, } \\
\text { fermentasi 2-3 minggu }\end{array}$ & $55 \%$ \\
\hline TOTAL & $100 \%$ \\
\hline
\end{tabular}

Dari Tabel 2. Menunjukkan bahwa masyarakat peternak mampu melakukan pengumpulan kotoran ternak dan perakitan biogas sebanyak 45\%, sedangkan masyarakat lebih paham mengenai proses pengenceran, pencampuran kototoran dengan air, dan fermentasi sebesar 55\%.

Lumpur hasil keluaran dari reaktor biogas diolah kembali untuk dijadikan pupuk organik yang disebut Bio-slurry, melalui cara disaring menggunakan kain kasa kemudian airnya ditampung ke 
dalam drum plastik. Untuk meningkatkan kualitasnya, perlu ditambahkan EM $_{4}$ (Efektive Mikroorganisme 4) kemudian dibiarkan selama 7 hari, proses selanjutnya dilakukan pengecekan setiap satu minggu sekali dengan ketentuan pengukuran karakterstik, $\mathrm{pH}$, dan suhu. Pupuk organik dari limbah biogas memiliki kandungan $\mathrm{N}$ total, amonium, dan $\mathrm{pH}$ lebih tinggi daripada limbah pertanian yang dikomposkan, sedangkan rasio C/N menurun dari 10,7 menjadi 7 sehingga memiliki kualitas yang baik (Insam et al. 2015).

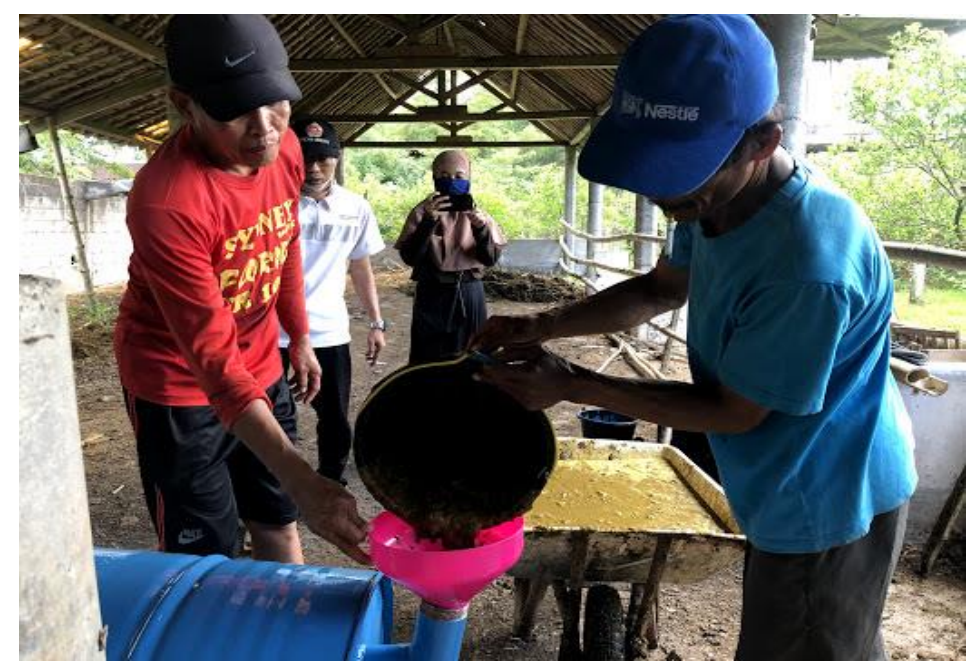

Gambar 2. Kotoran yang Telah Diencerkan

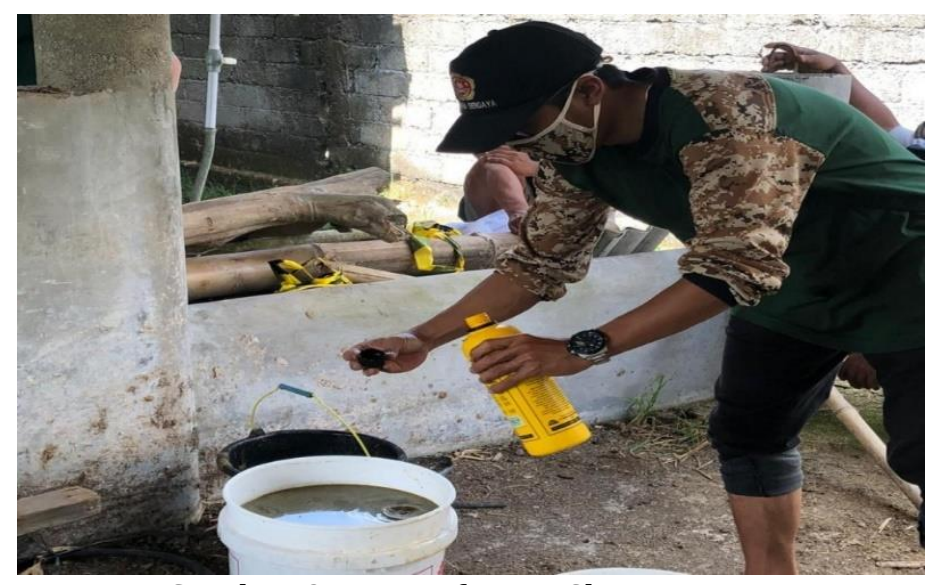

Gambar 3. Pemanfaatan Slurry Biogas

Tabel 3. Pemanfaatan Slurry Biogas

\begin{tabular}{|c|c|}
\hline $\begin{array}{l}\text { Apakah Masyarakat setuju slurry biogas dimanfaatkan untuk pembuatan } \\
\text { pupuk organik dan diaplikasikan pada tanaman maupun perkebunan }\end{array}$ & $\begin{array}{l}\text { Persentase } \\
\quad(\%)\end{array}$ \\
\hline 1. Sangat Setuju & $95 \%$ \\
\hline 2. Kurang Setuju & $5 \%$ \\
\hline 3. Tidak Setuju & $0 \%$ \\
\hline TOTAL & $100 \%$ \\
\hline
\end{tabular}

Berdasarkan tabel diatas diketahui bahwa peternak 95\% setuju dengan pengadaan pemanfaatan slurry dan diaplikasikan pada tanaman maupun perkebunan. Sedangkan masyarakat yang kurang setuju sebesar 5\% karena ada beberapa peternak yang belum mengetahui proses pembuatannya. Pengaruh pembuatan pupuk organik terhadap produksi tanaman beragam tergantung kepada jenis dan kondisi tanah, kualitas benih, iklim, dan faktor-faktor lain. Namun, pada 
dasarnya pemakaian bio-slurry akan memberikan manfaat terhadap kesuburan tanah, Memperbaiki struktur fisik tanah sehingga tanah menjadi lebih gembur, meningkatkan kemampuan tanah mengikat atau menahan air lebih lama yang bermanfaat saat musim kemarau. kegiatan ini merupakan kegiatan yang terpadu model (zero waste) dimulai dari pemanfaatan limbah hasil peternakan berupa kotoran sapi kemudian digunakan menjadi biogas yang bermanfaat sebagai sumber energi alternatif pengganti kayu bakar, LPG maupun BBM, hasil limbah dari biogas yaitu bioslurry dimana hasil samping pembuatan biogas ini diolah kembali menjadi pupuk organik kemudian, diaplikasikan kepada tanaman atau perkebunan dan hasil perkebunan tersebut dapat dimanfaatkan kembali untuk ternak.

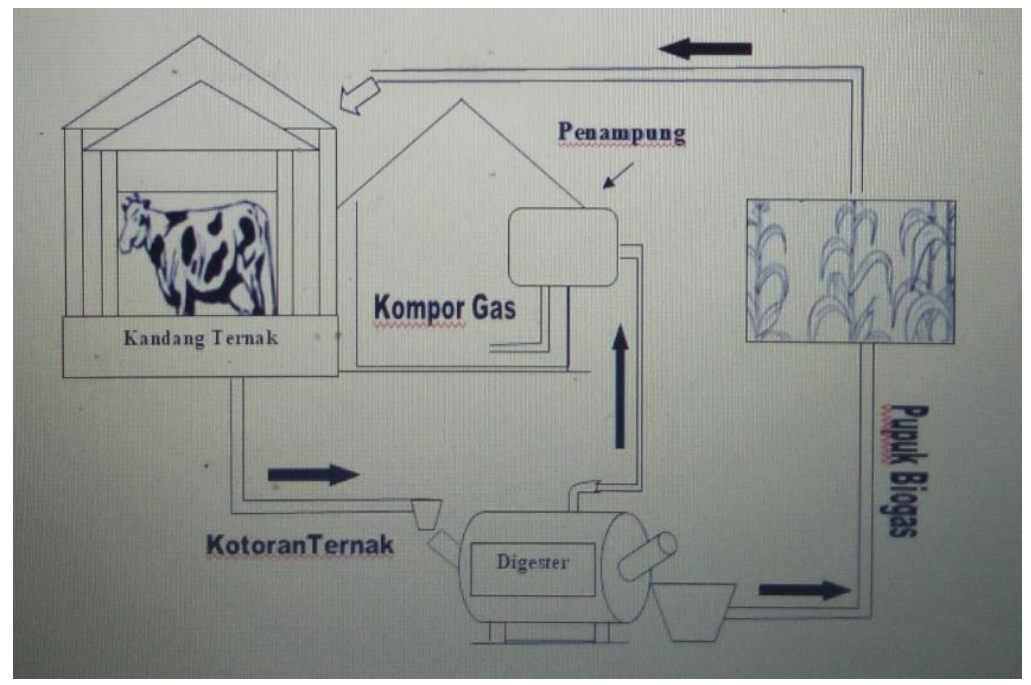

Gambar 4. Alur Model Zero Waste

Integrasi antara tanaman dan ternak yang disebut dengan petanian terpadu adalah memadukan antara kegiatan peternakan dan pertanian. Model ini sering disebut pola peternakan tanpa limbah karena limbah peternakan digunakan untuk pupuk, dan limbah pertanian digunakan untuk pakan ternak. Masing kompenen antara ternak dan tanaman harus saling melengkapi, mendukung dan saling menguntungkan, sehingga dapat mendorong peningkatan efisiensi produksi dan meningkatkan keuntungan hasil usaha taninya (Azhar Amir, 2016). Model Zero Waste mengarahkan pada konsep produk pangan (food), sumber pakan ternak (feed), energi terbarukan (fuel) dan kesuburan tanah (fertilizer). Konsep integrasi sapi perah dan tanaman pertanian berupa rumput maupun limbah pertanian jagung dapat disajikan pada Gambar 4.

Kegiatan ini memberikan pemahaman dan merubah pola pikir masyarakat mengenai penanganan dan pengolahan kotoran sapi yang selama ini dianggap hanya sebagai limbah, disamping itu ternyata memiliki banyak manfaat dari segi ekonomi yang dapat mengurangi pembelian bahan bakar kayu bakar dan gas LPG, dari sudut pandang mengenai lingkungan dapat tertangani dengan baik dan terjaga. Melalui kegiatan ini diharapkan dapat memberikan contoh baik bagi peternak lainnya tentang bagaimana memanfaatkan kotoran sapi sebagai sumber energi alternatif dan pemanfaaatan hasil samping biogas menjadi pupuk organik yang akan memberikan timbal balik pada ternak dan usaha ternaknya.

\section{KESIMPULAN}

Berdasarkan hasil pembahasan diatas terkait studi kasus yang dilakukan di kecamatan Glagahagung maka dapat disimpulkan bahwa peran peternak dalam pengelolaan limbah kotoran sapi cukup baik, hal ini dapat dilihat dari inisiatif yang sudah terbentuk, serta antusiasme peternak 
dalam mengolah limbah kotoran sapi menjadi biogas dan pupuk dari slurry dan keberhasilan peran masyarakat dalam mengelola limbah kotoran sapi secara komprehensif hal ini terbukti semakin sedikitnya limbah kotoran sapi untuk saat ini karena semua sudah dipergunakan sehingga akan menuju zero waste dengan memanfaatkan limbah kotoran sapi yang diolah dijadikan biogas dan pupuk yang berguna meningkatkan kualitas hidup tanaman sehingga lingkungan tempat tinggal menjadi lebih hijau, rindang dan sejuk

\section{DAFTAR PUSTAKA}

Azhar, A. (2016). Potensi Model Zero Waste dengan Integrasi Sapi Perah dan Ubi Kayu di Jawa Barat. Puslitbang: Kemendesa, PDT, dan Transmigrasi.

Dewi, R. P., \& Kholik, M. (2018). Kajian potensi pemanfaatan biogas sebagai salah satu sumber energi alternatif di wilayah magelang. Journal of Mechanical Engineering, 2(1), 8 - 14.

Dianawaty, M. (2015). Peluang pengembangan biogas di sentra sapi perah. Jurnal Litbang Pert, 34(3), 125-134.

Insam, H., Brandon, M.G. \& Ascher, J. (2015). Manure-based biogas fermentation residues: friend or foe of soil fertility soil boil. Biochem, 84, 1-14.

Megawati \& Aji, K.W. (2015). Pengaruh penambahan EM $_{4}$ (Effective Microorganism-4) pada pembuatan biogas dari eceng gondok dan rumen sapi. JBAT, 4(2), 42-49.

Wahyuni, S. (2015). Panduan Praktis Biogas. Jakarta Timur: Penebar Swadaya. 